\title{
PRECISION DOUBLET OF MAGNETIC QUADRUPOLE LENSES FOR ION BEAM FORMATION
}

\author{
A.G. Ponomarev, V.A. Rebrov, S.V. Kolinko, V.F. Salivon \\ Institute of Applied Physics, National Academy of Sciences of Ukraine, Sumy, Ukraine \\ E-mail: ponom56@gmail.com
}

The precision doublet of magnetic quadrupole lenses is presented. The doublet yoke and poles made from a single piece of soft magnetic iron. Doublet manufacturing technology provides of alignment of the geometric axes in the lenses with an accuracy of a few microns. The doublet geometry was chosen to obtain the maximum magnetic induction at the poles for a given radius of the lens aperture as a result of numerical simulation. An experimental study of the doublet properties was carried out using a setup for field reconstruction technique for magnetic quadrupole lenses. The relative position of the physical axes of the lenses (the geometrical location of points with zero magnetic induction) and the magnitudes of the parasitic multipole field components were determined.

PACS: 07.55.Db; 41.85.Lc; 41.20.Gz

\section{INTRODUCTION}

Magnetic quadrupole lenses are widely used both for beam transportation ${ }^{1}$ and formation of microprobes $[2$ 4]. The physical feature of the magnetic quadrupoles is that the mismatch of the beam axis with the lens axis leads to beam deflection. This requires additional correction of the beam position. The problem of alignment of the beam axis with axis of the single quadrupole does not have an unambiguous solution, since under the beam monitoring its position can be changed both by translational displacement of the lens in the transverse direction, and by tilting the lens relative to the transverse axes of the coordinate system associated with the axis of the beam. Due to the fact that the quadrupole has natural astigmatism, systems from several lenses are usually used. In this case, the problem of precise alignment can be solved by combining the lenses into an integrated module, when the axes of several lenses are combined structurally by means of the manufacturing of a single yoke and poles using wire electrical discharge machining [5] or a special rigid module is used in which the lenses are previously aligned $[6,7]$. The axis of such an integrated module of magnetic quadrupole lenses can be aligned with the axis of the beam with high accuracy. The alignment procedure in this case consists in the alternating excitation of the module's lenses, lateral displacements and tilts of the module as a single unit with monitoring of the beam position as a feedback.

In this work, we are considered the doublet of magnetic quadrupole lenses, the yoke and poles of which are a single unit and are made of the solid piece of soft magnetic iron using wire electrical discharge machining. This ensures the accuracy of the geometric coincidence of the axes of the doublet lenses less than $5 \mu \mathrm{m}$.

\section{SIMULATION AND DESIGN OF DOUBLET}

The geometry of the yoke and the poles of the doublet of quadrupole lenses was determined on numerical simulation of the distribution of magnetic induction as a function of the current in the coils. The shape of the surface of the poles has the form of truncated hyperbolas in order to minimize the magnitude of the parasitic sextupole and octupole field components. Fig. 1 shows the distribution of the magnetic induction at a current in the coils of 1200 Ampere-turns. From this figure it can be seen that only the outer edges of the poles are most saturated. The central part of the poles does not reach levels of field strength when saturation occurs. This makes it possible to increase the magnetic induction in the pole gap for a given radius of the lens aperture.

$$
\begin{aligned}
& \text { B, T } \\
& -2.0 \\
& -1.9 \\
& -1.8 \\
& -1.7 \\
& -1.6 \\
& -1.5 \\
& -1.4 \\
& -1.3 \\
& -1.2 \\
& -1.1 \\
& 0.0
\end{aligned}
$$

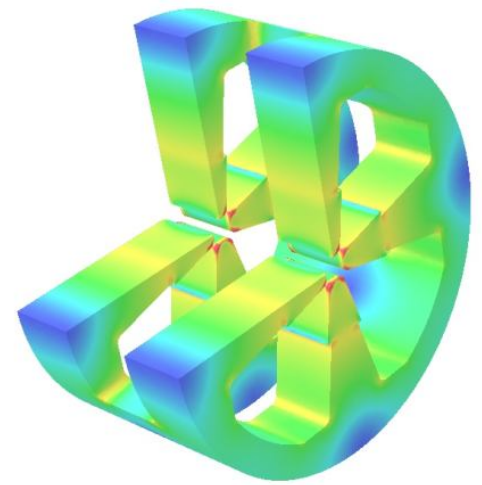

Fig. 1. Distribution of the magnetic induction vector module in the yoke and poles of the doublet of magnetic quadrupole lenses

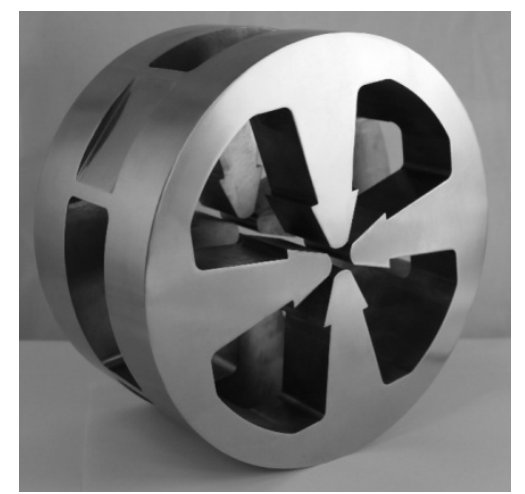

Fig. 2. Doublet yoke and poles as a single unit. Reproduced with permission from Ref. [8]. Copyright 2017 Elsevier B.V.

Fig. 2 shows the yoke and poles of the doublet as a single unit. The yoke and poles are nickel plated. The geometric dimensions of the doublet: outer diameter $235 \mathrm{~mm}$, aperture radius $6.5 \mathrm{~mm}$. The length of each lens is $40 \mathrm{~mm}$. The distance between the lenses is $45 \mathrm{~mm}$. The general view of the doublet mounted on the positioning table with five degrees of freedom is shown in Fig. 3. The current coils of the doublet lenses are made of copper plates with a cross section of $(0.8 \times 20) \mathrm{mm}^{2}$, which are soldered each to other according to the type of puzzles. Each coil has 44 turns. 


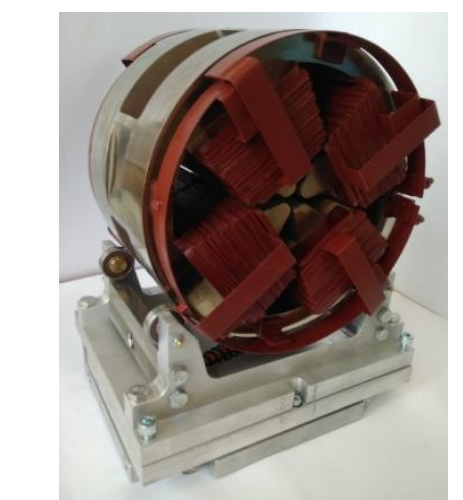

Fig. 3. Doublet assembly, mounted on the positioning table

\section{MEASUREMENTS SETUP}

To measure the field structure in each of the doublet lenses, the field reconstruction technique [9] is used, in which the radial component of the magnetic induction $B_{r}$ is measured on a virtual cylindrical surface $G$ inside the working gap of the lenses. The calculation of the induction at any point of the internal volume is based on the solution of the Neumann boundary problem for the Laplace equation. The measured $B_{r}$ values are used as boundary condition.

$$
\begin{gathered}
\Delta w(x, y, z)=0, \\
\left.B_{r}(x, y, z)\right|_{(x, y, z) \in G}=-\left.\frac{\partial w(x, y, z)}{\partial n}\right|_{(x, y, z) \in G},
\end{gathered}
$$

where $w(x, y, z)$ is the spatial distribution of the scalar magnetic potential in the region of the beam motion, and $n$ is the external normal to the surface $G$.

The solution of equation (1) is carried out by the integral method of boundary elements. This is important, since hereinafter it is necessary to calculate the partial derivatives of the scalar potential, which in this method is done by differentiating the kernel of the integral equation. This approach provides high accuracy calculations.

A setup layout that implements measurements of the radial component of magnetic induction is shown in Fig. 4. The setup parameters are described more detail in work [6].

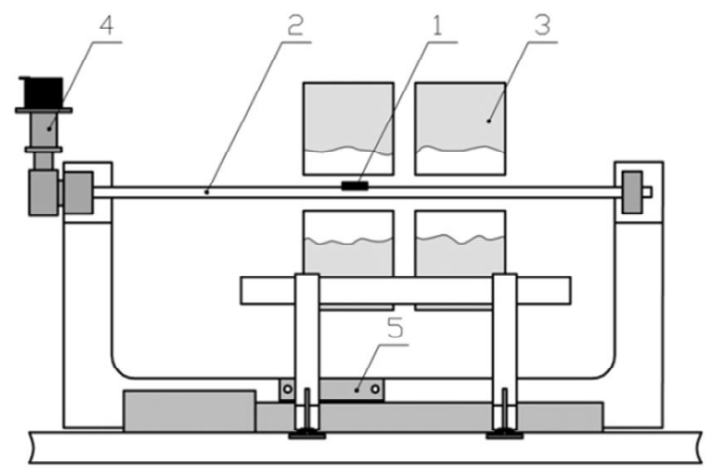

Fig. 4. Layout of the setup to investigate the field of magnetic quadrupole lens.

Reproduced with permission from Ref. [6]. Copyright 2013 Elsevier B. $V$.

Here the Hall probe 1 is mounted on the lateral surface of the tube $\mathbf{2}$ made of nonmagnetic material that passes through the working gaps of the magnetic quadrupole lenses 3 under study. The tube can be rotated about its axis by means of an angular positioning module 4 and moved along its axis by means of a linear positioning module 5 driven by stepper motors. In this case the Hall probe traverses the cylindrical surface sensing the magnetic induction vector component normal to this surface. A general view of the setup is presented in Fig. 5.

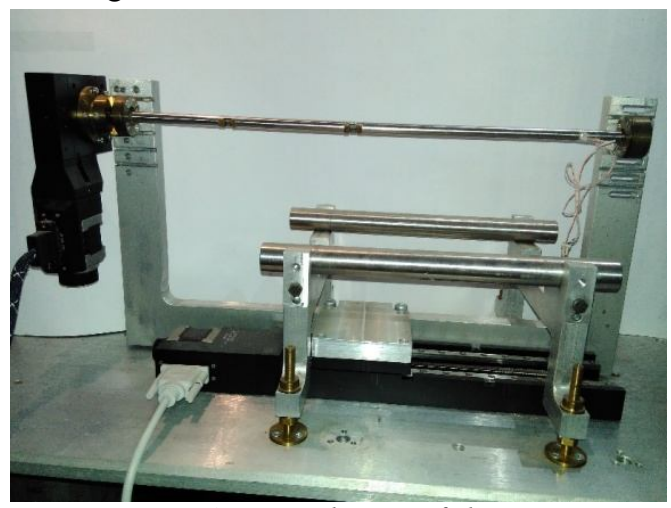

Fig. 5. A general view of the setup

The position of the physical axis of the lens is determined by the geometrical location of the points $x_{0}(z)$, $y_{0}(z)$ by solving the system of equations

$$
\begin{aligned}
& B_{x}\left(x_{0}, y_{0}, z\right)=-\left.\frac{\partial w(x, y, z)}{\partial x}\right|_{x=x_{0}, y=y_{0}}=0, \\
& B_{y}\left(x_{0}, y_{0}, z\right)=-\left.\frac{\partial w(x, y, z)}{\partial y}\right|_{x=x_{0}, y=y_{0}}=0 .
\end{aligned}
$$

In the local coordinate system of the lens associated with its physical axis and antisymmetry planes, the scalar magnetic potential can be represented as

$$
\begin{aligned}
& w(x, y, z)=2 W_{2}(z) x y+U_{3} x^{3}+3 W_{3}(z) x^{2} y- \\
& -3 U_{3}(z) x y^{2}-W_{3}(z) y^{3}+U_{4}(z) x^{4}+ \\
& +\left(4 W_{4}(z)-\frac{W_{2}^{\prime \prime}(z)}{6}\right) x^{3} y-6 U_{4}(z) x^{2} y^{2}- \\
& -\left(4 W_{4}(z)-\frac{W_{2}^{\prime \prime}(z)}{6}\right) x y^{3}+U_{4}(z) y^{4}+\cdots,
\end{aligned}
$$

where $W_{2}(z)$ - main quadrupole field component;

$W_{3}(z), U_{3}(z)$ - main and rotational sextupole parasitic components, respectively;

$W_{4}(z), U_{4}(z)$ - main and rotational octupole parasitic components, respectively.

Then all components can be determined by differentiating the scalar magnetic potential (3) and equating the transverse coordinates to zero in the form

$$
\begin{aligned}
& W_{2}(z)=\left.\frac{1}{2} \frac{\partial^{2} w(x, y, z)}{\partial x \partial y}\right|_{x=0, y=0}, \cdots \\
& U_{4}(z)=\left.\frac{1}{6} \frac{\partial^{4} w(x, y, z)}{\partial x^{2} \partial y^{2}}\right|_{x=0, y=0}, \cdots
\end{aligned}
$$

\section{MEASUREMENTS AND RESULTS OF FIELD RECONSTRUCTION}

Magnetic induction measurements at the poles of the doublet lenses were carried out using a teslameter with a relative measurement error of $10^{-3}$. The dependence of 
magnetic induction on the current in the coils is shown in Fig. 6. From this figure it is seen that this dependence is close to linear in the entire range of currents when aircooling of coils are not required.

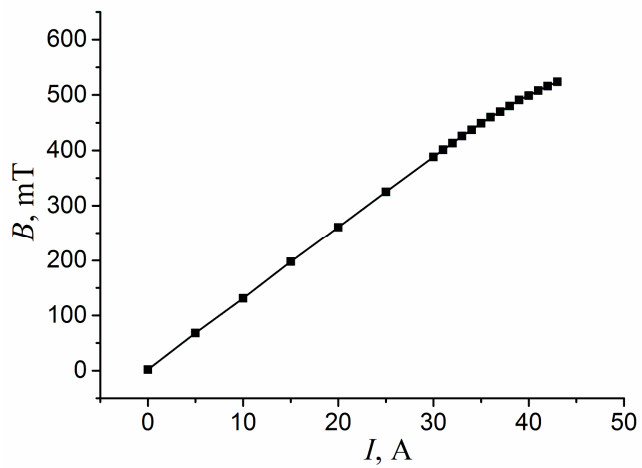

Fig. 6. Dependence of magnetic induction of one of the poles of the doublet lenses via the current in the coils

The alignment of the doublet lenses was determined using the method described above. The geometrical location of the points is shown in Fig. 7 at which the condition $|\vec{B}|=0$ is fulfilled for each of the lenses in the coordinate system associated with the axis of rotation of the Hall probe. Closer to the edges, a certain deviation of the axis from the straight line is observed, which is associated with a decreasing of magnetic induction in this region and, as a result, increasing of the error of the field reconstruction technique. Perhaps this effect can be associated with the physical feature of the uneven magnetization of the lens edges, as can be seen from Fig. 1 under simulation. The axis position of each lens was determined by linear approximation of the points obtained by reconstructing the field structure from (2). The position of the doublet axis was determined by approximating all points of both lenses. Calculations show that the maximum misalignment of the lens axes with the doublet axis does not exceed $0.2 \mathrm{mrad}$.

An important characteristic of each magnetic quadrupole lens is the magnitude of the multipole parasitic field components, which are associated with geometric and physical imperfections. In accordance with (4), the longitudinal distribution of parasitic sextupole and octupole components of the magnetic field was determined. Fig. 8 shows this distribution. It can be seen from this figure that the parasitic components have a fairly low level relative to the main quadrupole component, which determines the high quality of the doublet.

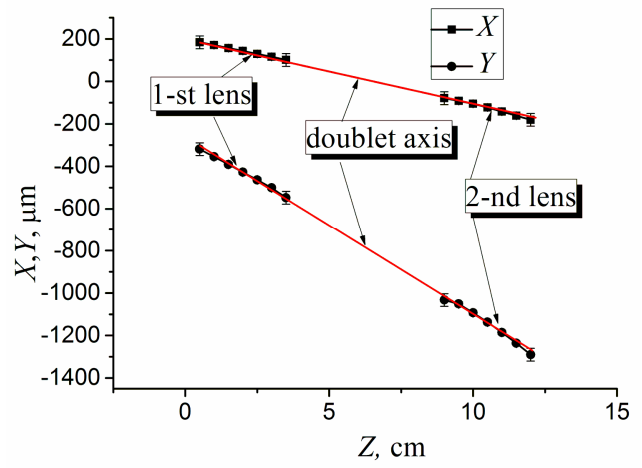

Fig. 7. Determination of the alignment of the doublet lenses

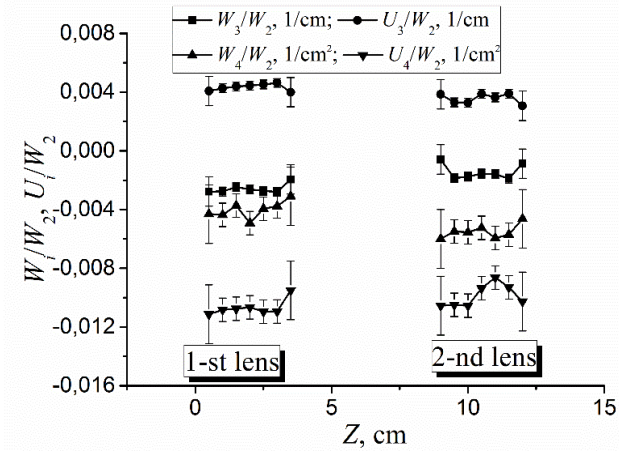

Fig. 8. Longitudinal distribution of the parasitic field components in the doublet lenses

\section{CONCLUSIONS}

A precision doublet of magnetic quadrupole lenses in which the yoke and poles are a single unit is considered. Such a doublet has the property of accurate alignment relative to the axis of the beam. Due to the applied wire cutting electrical discharge machining the noncoaxiality of the doublet lenses is less than $0.2 \mathrm{mrad}$. Relative parasitic sextupole components in the lenses are at a level of $0.004 \mathrm{~cm}^{-1}$, parasitic octupole components at a level of $0.01 \mathrm{~cm}^{-2}$.

\section{REFERENCES}

1. K.G. Steffen. High energy beam optics. Interscience Publishers, 1965, $211 \mathrm{p}$.

2. G.W. Grime, F. Watt. Beam optics of quadrupole probe-forming systems. Bristol, UK: Adam Hilger Ltd. 1984, 273 p.

3. A.A. Ponomarova, K.I. Melnik, G.S. Vorobjov, A.G. Ponomarev. One-stage probe-forming systems with quadrupole lenses excited by individual power supplies // Nucl. Instr. and Meth. B. 2011, v. 269, p. 2202-2205.

4. K.I. Melnik, D.V. Magilin, A.G. Ponomarev. Experimental results of microprobe focusing by quadruplet with four independent lens power supplies // Nucl. Instr. and Meth. B. 2013, v. 306, p. 17-20.

5. V.A. Rebrov, A.G. Ponomarev, V.K. Palchik, N.G. Melnik. The new design of magnetic quadrupole lens doublet manufactured from a single piece // Nucl. Instr. and Meth. B. 2007, v. 260, p. 34-38.

6. S.V. Kolinko, A.G. Ponomarev, V.A. Rebrov. Precise centering and field characterization of magnetic quadrupole lenses // Nucl. Instr. and Meth. A. 2013, v. 700, p. 70-74.

7. O.S. Lapin, S.V. Kolinko, V.A. Rebrov, V.F. Salivon, A. Ponomarov, A.G. Ponomarev. Precise centering method for triplet of magnetic quadrupole lenses using single rigid frame // Nucl. Instr. and Meth. B. 2017, v. 404, p. 41-44.

8. A. Ponomarov, I. Rajta, G. Nagy, O.V. Romanenko. Single-stage quintuplet for upgrading triplet based lens system: Simulation for Atomki microprobe // Nucl. Instr. and Meth. B. 2017, v. 404, p. 34-40.

9. S. Lebed, A. Ponomarev. Field reconstruction technique for testing magnetic quadrupole lenses // Nucl. Instr. and Meth. B. 1997, v. 130, p. 90-96.

Article received 17.03.2020 


\section{ПРЕЦИЗИОННЫЙ ДУБЛЕТ МАГНИТНЫХ КВАДРУПОЛЬНЫХ ЛИНЗ ДЛЯ ФОРМИРОВАНИЯ ПУЧКОВ ИОНОВ}

\section{А.Г. Пономарев, В.А. Ребров, С.В. Колинько, В.Ф. Саливон}

Рассмотрен прецизионный дублет магнитных квадрупольных линз. Ярмо и полюса дублета изготовлены из цельного куска магнитомягкого железа. Технология изготовления дублета обеспечивает соосность геометрических осей в линзах с точностью до нескольких микрометров. Геометрия дублета была выбрана с целью получения максимальной магнитной индукции на полюсах для заданного радиуса апертуры линзы в результате численного моделирования. Экспериментальное исследование свойств дублета проводилось на установке для восстановления поля в магнитных квадрупольных линзах. Определены относительное положение физических осей линз (геометрическое расположение точек с нулевой магнитной индукцией) и величины паразитных мультипольных компонент поля.

\section{ПРЕЦИЗІЙНИЙ ДУБЛЕТ МАГНІТНИХ КВАДРУПОЛЬНИХ ЛІНЗ ДЛЯ ФОРМУВАННЯ ПУЧКІВ ІОНІВ}

\section{О.Г. Пономарьов, В.А. Ребров, С.В. Колінько, В.Ф. Саливон}

Розглянуто прецизійний дублет магнітних квадрупольних лінз. Ярмо і полюса дублета виготовлені 3 цілісного шматка магнітом'якого заліза. Технологія виготовлення дублета забезпечує співвісність геометричних осей в лінзах з точністю до декількох мікрометрів. Геометрія дублета була обрана 3 метою отримання максимальної магнітної індукції на полюсах для заданого радіуса апертури лінзи в результаті чисельного моделювання. Експериментальне дослідження властивостей дублета проводилося на установці для відновлення поля в магнітних квадрупольних лінзах. Визначено відносне положення фізичних осей лінз (геометричне розташування точок з нульовою магнітною індукцією) і величини паразитних мультипольних компонент поля. 